\title{
Effect of Ketotifen on Acute Gastric Lesions and Gastric Secretion in Rats
}

\author{
Susumu Okabe, Shigeru Nakaji and Masaki Tachibana \\ Department of Applied Pharmacology, Kyoto Pharmaceutical University, Misasagi, Yamashina, Kyoto 607, Japan \\ Received February 27, 1992 Accepted April 10, 1992
}

\begin{abstract}
Ketotifen, a histamine $\mathrm{H}_{\mathbf{1}}$-receptor antagonist and mast cell stabilizer, significantly protected the rat gastric mucosa against lesions induced by necrotizing agents, histamine or compound 48/80. The agent significantly inhibited the basal gastric acid secretion, but had little or no effect on the histamine-stimulated secretion. The mucosal protective effect was observed even at a dose that had little or no effect on gastric acid secretion, suggesting that ketotifen exhibits so-called cytoprotective activity.
\end{abstract}

Keywords: Ketotifen, Acute gastric lesions, Cytoprotection

Ketotifen is an antianaphylactic drug used for the prevention of asthma or various allergic diseases, most probably due to its histamine $\mathrm{H}_{1}$-receptor antagonistic and mast cell stabilizing activities (1-3). Interestingly, Karmeli et al. (4) recently found that it could prevent the development of ethanol-induced gastric lesions in rats. We thus examined whether or not ketotifen protects the gastric mucosa against acute gastric lesions induced by several necrotizing agents including ethanol, histamine or compound $48 / 80$. The effects of ketotifen on gastric basal and histamine-stimulated acid secretion were also studied to elucidate the mechanism of action of the drug.

Male Sprague-Dawley rats $(240-260 \mathrm{~g})$ were deprived of food for $24 \mathrm{hr}$ before the induction of gastric lesions, except for in the case of compound $48 / 80$-induced lesions (no fasting before or during the experiment) and gastric secretory studies. Tap water was given freely during fasting, but withheld during the last $2 \mathrm{hr}$. Necrotizing agent-induced gastric lesions were produced by administering p.o. $1 \mathrm{ml} / 200 \mathrm{~g}$ body wt. of either $100 \%$ ethanol $(v / v)(5), 60 \%$ ethanol $(v / v)$ in $150 \mathrm{mM} \mathrm{HCl}(\mathrm{HCl} \cdot$ ethanol) (6), or aspirin $(150 \mathrm{mg} / \mathrm{kg}$, Nacalai Tesque) in $150 \mathrm{mM} \mathrm{HCl}(\mathrm{HCl} \cdot$ aspirin) (7). The animals were killed $1 \mathrm{hr}$ later, and their stomachs were removed and then inflated with $8 \mathrm{ml}$ of $2 \%$ formalin for $10 \mathrm{~min}$. Subsequently, the length $(\mathrm{mm})$ of each lesion in the glandular portion was determined under a dissecting microscope $(\times 10)$ and summed per stomach. Ketotifen (Sandoz), dissolved in saline, or the vehicle alone was administered p.o. $0.5 \mathrm{hr}$ before the administration of each necrotizing agent in a volume of $1 \mathrm{ml} /$ animal. Histamine-induced gastric lesions were produced as previously described (8). Briefly, the abdomen was incised under ether anesthesia, and both the gastric artery and vein were ligated. The gastro-epiploic artery and vein remained intact. Immediately after the ligation of blood vessels, the pylorus were ligated. After the abdomen had been closed, histamine $\cdot 2 \mathrm{HCl}$, dissolved in saline, was administered s.c. at $40 \mathrm{mg} / \mathrm{kg}$ (as the salt). The animals were killed $3 \mathrm{hr}$ later. The area $\left(\mathrm{mm}^{2}\right)$ of each lesion in the glandular portion was determined and summed per stomach. Ketotifen or the vehicle alone was administered p.o. $0.5 \mathrm{hr}$ before the ligation of vessels. Compound 48/80 (Sigma), dissolved in saline, was administered i.p. at $0.75 \mathrm{mg} / \mathrm{kg}$ in a volume of 0.4 $\mathrm{ml} /$ rat once daily (9:30 AM) for 4 days (9). The animals were killed $24 \mathrm{hr}$ after the final administration of the agent. The area $\left(\mathrm{mm}^{2}\right)$ of each lesion in the glandular portion was determined and summed per stomach. Ketotifen or the vehicle alone was administered p.o. twice a day (9:00 AM and 6:00 PM) for 4 days.

Gastric secretory studies were performed as follows: In the case of basal secretion, the abdomen of each rat was incised under ether anesthesia and the pylorus ligated. The animals were killed $4 \mathrm{hr}$ after the pylorus ligation, and the gastric contents collected and analyzed as to the volume $(\mathrm{ml} / \mathrm{hr})$ and acidity $(\mathrm{mEq} / \mathrm{l})$. The acidity was determined by titration of the gastric contents against $0.1 \mathrm{M} \mathrm{NaOH}$ to $\mathrm{pH} 7.0$ with an autoburette 
(Comtite B, Hiranuma). Acid output (volume $\times$ acidity) was expressed as $\mu \mathrm{Eq} / \mathrm{hr}$. Ketotifen or the vehicle alone was administered p.o. $0.5 \mathrm{hr}$ before the ligation. As to stimulated secretion, the abdomen was incised under ether anesthesia, and the stomach and duodenum exposed. A polyethylene cannula ( $7 \mathrm{~mm}$, ID) was introduced into the stomach through the forestomach and secured tightly with two purse-string sutures. The cannula had two small polyethylene tubes $(1.5 \mathrm{~mm}$, ID) attached, one of which was inserted into the distal part of the esophagus to exclude saliva from the gastric samples and the other into the proximal duodenum through the pylorus to inject ketotifen (10). The pylorus was then ligated together with the tube. After recovery from anesthesia, the animals were placed in Bollman cages, and gastric juice was collected. The first $0.5-\mathrm{hr}$ sample was discarded, and the following 2-hr sample was used for measurement of the basal secretion. Histamine $\cdot 2 \mathrm{HCl}$, dissolved in saline, was injected s.c. at $20 \mathrm{mg} / \mathrm{kg}$ twice, with a $2-\mathrm{hr}$ interval. Gastric samples were collected $4 \mathrm{hr}$ later, and the volume and acid output were expressed as $\mathrm{ml} / \mathrm{hr}$ and $\mu \mathrm{Eq} / \mathrm{hr}$, respectively. Ketotifen or the vehicle alone was administered once intraduodenally (i.d.) $0.5 \mathrm{hr}$ prior to the first administration of histamine. Dunnett's method was employed to determine the statistical significance of the data obtained in this study, at the level of $\mathbf{P}<0.05$. The $E D_{50}$ values (the doses that inhibit gastric acid output and gastric or duodenal lesions by $50 \%$ ) and $95 \%$ confidence limits were calculated by the Litchfield-Wilcoxon method.

Each of the necrotizing agents induced gastric mucosal damage with the incidence of $100 \%$. The means ( \pm standard error) of the total length of these lesions per rat were $112.9 \pm 6.5,136.3 \pm 3.1$ and $91.9 \pm 7.2$ $\mathrm{mm}(\mathrm{n}=8)$ for ethanol-, $\mathrm{HCl} \cdot$ ethanol- and $\mathrm{HCl}$ aspirin-induced lesions, respectively. Ketotifen significantly protected the gastric mucosa against these necrotizing agent-induced lesions (Fig. 1). The protection was not dose-dependent in the case of ethanol-induced lesions, whereas the drug protected against the latter two lesions in a dose-dependent manner. With 30 $\mathrm{mg} / \mathrm{kg}$, the level of protection against these lesions was almost $>90 \%$. The $\mathrm{ED}_{50}$ value $(95 \%$ confidence limit) of ketotifen for the above lesions was $5.0(2.1-11.0)$, $6.0(3.1-15.7)$ and $3.2(1.7-5.1) \mathrm{mg} / \mathrm{kg}$, respectively. Histamine and compound $48 / 80$ also apparently induced gastric mucosal damage with the incidence of $100 \%$. The means ( \pm standard error) of the total area of these lesions were $140.6 \pm 27.9$ and $110.8 \pm 20.2$ $\mathrm{mm}^{2}(\mathrm{n}=8)$ for histamine- and compound 48/80induced lesions, respectively. Ketotifen also markedly prevented the development of these lesions in a dosedependent manner. In the case of the latter lesions, nearly complete protection was observed with the dose of $0.3 \times 2 \mathrm{mg} / \mathrm{kg} / \mathrm{day}$. The $\mathrm{ED}_{50}$ value for these lesions was 1.8 and $0.01 \mathrm{mg} / \mathrm{kg}$, respectively. Ketotifen had almost no or very little effect on gastric basal and histamine-stimulated acid secretion when administered at $1-10 \mathrm{mg} / \mathrm{kg}$ (Table 1). Although the agent had little

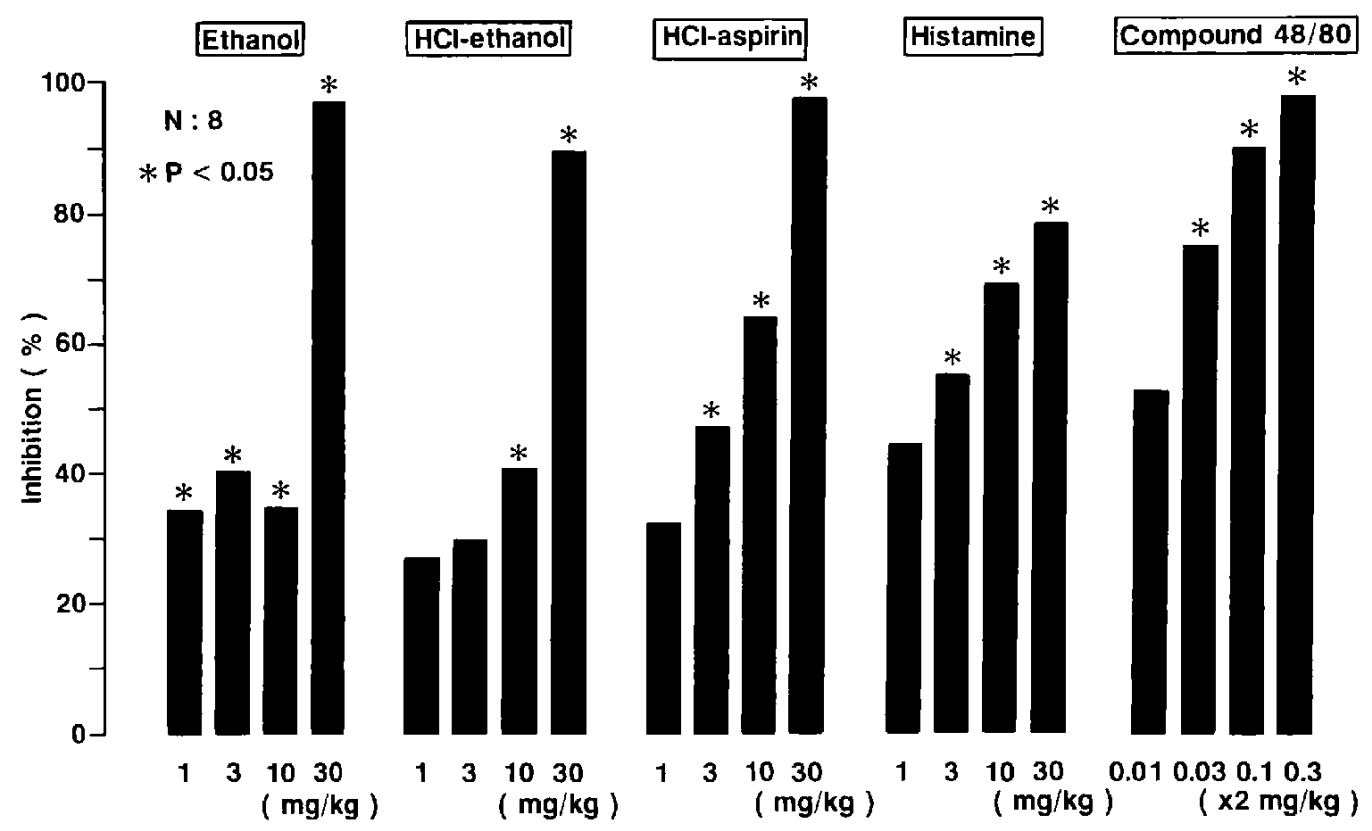

Fig. 1. Effect of ketotifen on the formation of gastric lesions induced by various agents in rats. ${ }^{*} \mathrm{P}<0.05$. 
Table 1. Effects of ketotifen on basal and histamine-stimulated gastric acid secretion in pylorus-ligated (4 hr) rats

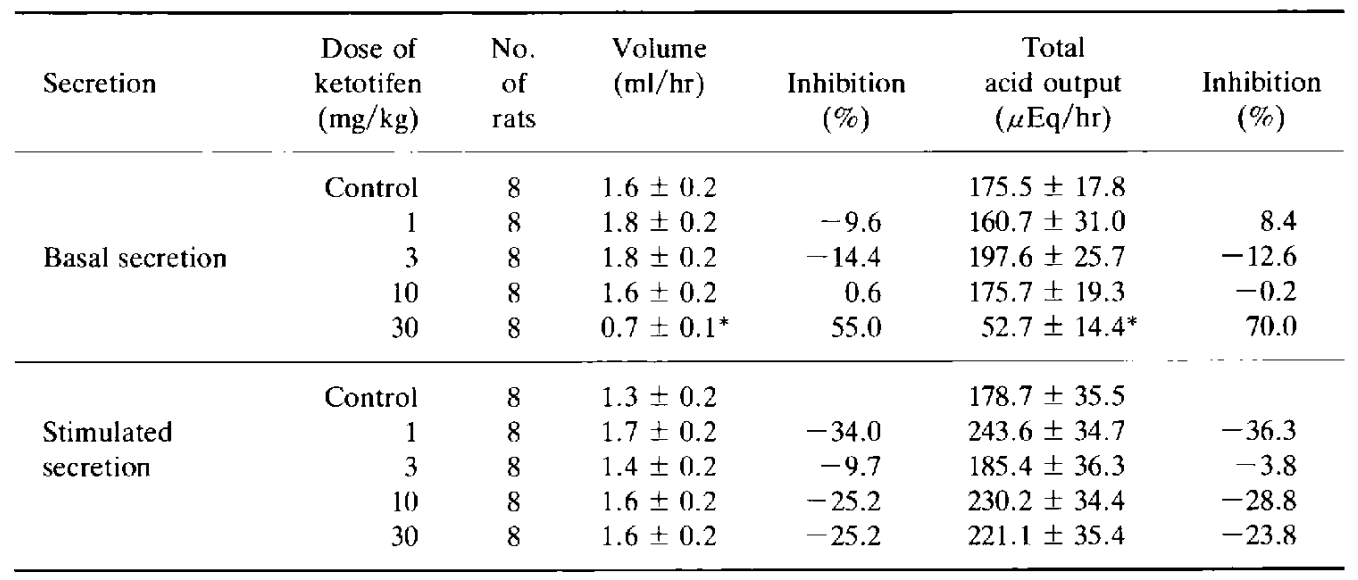

The agent was administered p.o. once $0.5 \mathrm{hr}$ before pylorus ligation (basal secretion) or s.c. $0.5 \mathrm{hr}$ before the first histamine administration (stimulated secretion). Histamine $\cdot 2 \mathrm{HCl}$ was administcred s.c. at 20 $\mathrm{mg} / \mathrm{kg}$ twice, with a 2 -hr interval. Data are means \pm S.E. ${ }^{*} \mathrm{P}<0.05$.

or no effect on histamine-stimulated secretion at doses of $1-30 \mathrm{mg} / \mathrm{kg}$, it significantly inhibited the basal acid secretion at $30 \mathrm{mg} / \mathrm{kg}$.

These results indicate that ketotifen has the ability to protect the gastric mucosa from necrotizing agents as well as histamine- and compound 48/80-induced lesions. Concerning ethanol-induced lesions, we confirmed the findings of Karmeli et al. (4), who observed complete protection against such lesions. The dose they used was only $1 \mathrm{mg} / \mathrm{kg}$, yet the dose required for nearly complete protection in our case was $30 \mathrm{mg} / \mathrm{kg}$. With 1 $\mathrm{mg} / \mathrm{kg}$ in the present study, significant, but only $34.4 \%$, inhibition of the lesions was observed. This discrepancy might be caused by the different methods used: they examined the lesion formation $10 \mathrm{~min}$ after ethanol administration, while we did so $1 \mathrm{hr}$ later. Their lesions appear to be less severe compared with our lesion model because of the short duration of ethanol exposure. The mechanism by which ketotifen, administered at 30 $\mathrm{mg} / \mathrm{kg}$, markedly protected the mucosa against ethanolinduced lesions remains unknown. The participation of $\mathrm{H}_{\mathrm{I}}$-receptors is unlikely because there was no dosedependent protection in contrast to histamine or compound 48/80-induced lesions. The same mucosal protective activity of ketotifen was observed for gastric lesions induced by acidified ethanol and aspirin. These results suggest that the mechanism underlying the mucosal protective action of ketotifen has at least no relationship to acid secretion. In addition, ketotifen at $10 \mathrm{mg} / \mathrm{kg}$ or less had no effect on basal gastric secretion, yet it significantly protected the gastric mucosa. These results suggest that ketotifen has a so-called cytoprotective effect as one of its pharmacological properties. At 30 $\mathrm{mg} / \mathrm{kg}$, it significantly inhibited the basal gastric acid secretion, but had little effect on the histamine-stimulated secretion. Therefore, it is likely that it acts by preventing the release of histamine from the mast or ECL-cells in the stomach. Interestingly, ketotifen apparently prevented the development of histamineinduced gastric lesions. The mechanism by which histamine induced gastric lesions in the present study remains unclear. Since sodium bicarbonate, cimetidine and omeprazole could inhibit the development of the lesions, it was assumed that acid is involved in the pathogenesis. In addition, an $\mathrm{H}_{\mathrm{l}}$-antagonist, tripelennamine, which had no effect on gastric secretion, markedly prevented the formation of the lesions. Therefore, it is most likely that similar to tripelennamine, ketotifen inhibited the histamine-induced lesions by antagonizing the action of histamine at the $\mathrm{H}_{1}$-receptors located on the mucosal blood vessels. In addition, ketotifen prevented compound $48 / 80$-induced gastric lesions. We have reported that the mechanism by which the agent induces gastric lesions is related to the release of histamine and serotonin from the mast cells (9). It appears that ketotifen inhibited the lesions by virtue of its mast cell stabilizing activity. These data suggest that ketotifen will be useful for the treatment of acute gastric lesions or ulcers due to its cytoprotective and mast cell stabilizing activities. Clinical studies on the effects of ketotifen on gastrointestinal diseases are suggested.

\section{REFERENCES}

1 Martin, U. and Romer, D.: The pharmacological properties of a new orally active antianaphylactic compound; ketotifen, 
a benzocyclo-heptathiophen. Arzneimittelforschung 28, $770-$ 782 (1978)

2 Ney, U.M., Bretz, U., Marin, U. and Mazzoni, L.: Pharmacology of ketotifen. Research and Clinical Forums 4, 9-16 (1982)

3 Morley, J., Sanjar, S., Boubekeur, K., Aoki, S. and Kristersson, A.: Pharmacological evaluation of prophylactic antiasthma drugs by reference to the pathological sequelae of exposure to an allergen or platelet activating factor. Agents Actions, Supp. 23, 187-194 (1988)

4 Karmeli, F., Eliakim, R., Okon, E. and Rachmilewitz, D.: Gastric mucosal damage by ethanol is mediated by substance $\mathrm{P}$ and prevented by ketotifen, a mast cell stabilizer. Gastroenterology 100, 1206-1216 (1991)

5 Robert, A., Nezamis, J.E., Lancaster, C. and Hanchar, A.J.: Cytoprotection by prostaglandins in rats. Prevention of gastric necrosis produced by alcohol, $\mathrm{HCl}, \mathrm{NaOH}$, hypertonic $\mathrm{NaCl}$, and thermal injury. Gastroenterology 77, 433-443 (1979)

6 Mizui, T. and Doteuchi, M.: Effect of polyamines on acidified ethanol-induced gastric lesions in rats. Japan. J. Pharmacol. 33, 939-945 (1983)

7 Guth, P.H., Aures, D. and Paulsen, G.: Topical aspirin plus $\mathrm{HCl}$ gastric lesions in the rat. Cytoprotective effect of prostaglandin, cimetidine and probanthine. Gastroenterology 76, $88-93(1977)$

8 Okabe, S. and Nakagawa, M.: A new method for production of acute gastric mucosal lesions by histamine in gastric arteryligated rats (Abstract). Gastroenterology 96, A375 (1989)

9 Takeuchi, K., Ohtsuki, H. and Okabe, S.: Pathogenesis of compound $48 / 80$-induced gastric lesions in rats. Dig. Dis. Sci. 31, $392-400$ (1986)

10 Okabe, S. and Kuwahara, Y.: Stimulation of gastric acid secretion by intraduodenally administered histamine in acute fistula rats (Abstract). Gastroenterology 96, A375 (1989) 